Revista de Economia Política, vol. 32, no 2 (127), pp. 213-228, abril-junho/2012

\title{
Teorias do comércio internacional: um debate sobre a relação entre crescimento econômico e inserção externa
}

UALLACE MOREIRA*

Theories of international trade: a debate on the relationship between economic growth and foreign market insertion. The paper analyzes the importance accorded to the high technology industry sector in the process of economic growth, in its relation to international trade. Considering at first liberal arguments that disregard productive and commercial specialization as a cause of unequal economic development, the paper discusses then some institutionalist and evolutionist arguments which, since List, stress that high technology specialization matters for the rate of increase of productivity and for the surmount for foreign exchange restrictions to growth.

Keywords: trade; economic development; theories of international trade.

JEL Classification: F000; F100; O300; O430.

\section{INTRODUÇÃO}

O artigo tem como objetivo analisar a importância conferida aos ramos industriais de alta tecnologia no processo de crescimento econômico, em sua relação com o comércio internacional. Em linhas gerais, há dois modos opostos de relacionar crescimento econômico e especialização produtiva e comercial. De um lado, a tradição liberal utiliza diversos argumentos e instrumentos analíticos para alcançar

\footnotetext{
* Doutorando em Desenvolvimento Econômico - Área de concentração em História Econômica - pelo Instituto de Economia da Universidade Estadual de Campinas (IE/Unicamp). Mestre em Desenvolvimento Econômico pelo Instituto de Economia da Universidade Estadual de Campinas (IE/Unicamp). Bacharel em Ciências Econômicas pela Faculdade de Ciências Econômicas da Universidade Federal da Bahia (FCE/UFBa). E-mail: uallacemoreira@hotmail.com. Submetido: 20/Julho/2010; Aprovado: $3 / \mathrm{março/2011.}$
} 
uma mesma conclusão: que o livre-comércio induz agentes econômicos a alocar recursos de modo a especializar países de acordo com perfis de eficiência produtiva desiguais mas complementares, levando-os a maximizar a riqueza das nações (ou o benefício dos consumidores), dados os recursos e capacitações existentes.

De outro lado, autores de diversas tradições antiliberais alegam que a existência de especializações produtivas diferenciadas tende a provocar interações comerciais assimétricas, com efeito desigual sobre a capacidade de geração de riqueza e acumulação de capacitações produtivas entre os países. Por isso, políticas de Estado vieram e devem vir a influenciar a alocação de investimentos de modo a buscar modificar a especialização produtiva e comercial legada por recursos e capacitações preexistentes. Neste sentido, as políticas vieram e devem especialmente buscar desenvolver ramos industriais de alta tecnologia, ou pelo menos elevar o grau de intensidade tecnológica da especialização produtiva nacional, propiciando ganhos de produtividade e competitividade que não resultariam espontaneamente do livre-comércio.

O primeiro item, a seguir, discute argumentos típicos da tradição liberal. $O$ segundo item aborda argumentos institucionalistas e evolucionistas que criticam teoricamente e procuram refutar empiricamente o liberalismo econômico, e o último item faz considerações finais.

\section{OS PRESSUPOSTOS LIBERAIS}

A teoria liberal do comércio internacional nasceu com o elogio da divisão do trabalho e a crítica do protecionismo feitos por Adam Smith em A Riqueza das Nações, de 1776. Segundo ele, quanto mais desenvolvida fosse a divisão do trabalho, mais especializado e eficiente seria o trabalho, e mais rica a nação. Como o aprofundamento da divisão do trabalho dependeria da extensão dos mercados, quanto mais abertos os mercados nacionais, mais ricas seriam as nações integradas pelo comércio. No célebre cap. II do livro IV d' A Riqueza das Nações, Smith alega que os indivíduos buscariam continuamente a aplicação mais vantajosa de seu capital (ou de seu trabalho), e teriam melhores condições do que estadistas ou legisladores de julgar por si mesmos qual o tipo de atividade nacional desenvolver. Outorgar o monopólio do mercado interno em qualquer ofício equivaleria a orientar pessoas particulares sobre como empregar seus capitais. Se o preço do produto nacional for mais elevado do que o importado, a norma seria necessariamente prejudicial: se um país estrangeiro estiver em condições de fornecer uma mercadoria a um preço mais baixo do que o da mercadoria fabricada internamente, seria melhor comprá-la com uma parcela da produção da própria atividade local, empregada de forma em que se aufira alguma vantagem. De nada interessaria se as vantagens que um país leva sobre outro sejam naturais ou adquiridas, pois a atividade da sociedade só poderia aumentar na proporção em que aumenta seu capital, e este só aumentaria na proporção em que se puder aumentar o que se poupa gradualmente de sua renda. Como o efeito imediato de todas as restrições às im- 
portações seria diminuir a renda do país, o que diminui essa renda não aumentaria o capital da sociedade mais rapidamente do que teria aumentado espontaneamente, caso se tivesse deixado o capital e a atividade encontrarem seus empregos naturais ${ }^{1}$.

Especializações determinadas por vantagens de custo de produção; livre concorrência alocando da melhor forma os recursos; complementaridade e harmonia na distribuição dos ganhos do comércio, independentemente do teor da especialização nacional: os grandes temas anunciados por Smith foram reelaborados mas nunca rejeitados pela tradição liberal que fundou. Já no início do século XIX, David Ricardo alegaria que as relações comerciais entre nações ocorreriam segundo o princípio das vantagens comparativas, e não absolutas: os países exportariam (importariam) bens produzidos onde trabalho fosse relativamente mais (menos) eficiente, de modo que o comércio seria favorável mesmo para um país que fosse mais (menos) eficiente em todas as linhas de produção².

A rejeição da doutrina do valor trabalho pela revolução marginalista não questionou o cerne da teoria das vantagens comparativas. A teoria neoclássica do comércio internacional foi desenvolvida por Eli F. Heckscher e aprimorada por Bertil G. Ohlin ${ }^{3}$. A ideia central é que o comércio internacional é explicado pelas diferenças de dotação de fatores de produção entre os países, isto é, os países tendem a exportar (importar) bens cuja produção dependa da abundância (escassez) de terra, trabalho e capital. A crítica dos autores suecos ao modelo clássico de Ricardo era a de que não bastava explicar a troca internacional pela lei dos custos comparativos, era necessário explicar por que os custos comparativos existiam. Para isso, seria necessário integrar ao fator trabalho os fatores terra e capital combinados em cada linha de produção: dadas as diferenças fatoriais entre os países, o comércio ocorreria até que o preço marginal dos fatores de produção fosse equalizado. Simplificando a apresentação com recurso a apenas dois fatores (terra e trabalho), dois produtos e dois países, o conjunto de supostos para legitimar o livre-comércio tornou-se formalmente mais rigoroso: a) o modelo é baseado em uma estrutura de mercado de concorrência perfeita nos mercados de bens e de fatores de produção; b) as funções de produção são similares entre as nações envolvidas no comércio internacional, diferentes entre os setores produtivos e apresentam rendimentos constantes de escala (isso implica que a variação na produção é exatamente igual à variação na utilização de todos os insumos); c) há livre mobilidade dos fatores de produção entre os setores produtivos, mas entre os países não existe livre mobilidade, com os preços totalmente flexíveis; d) os produtos e os fatores são homogêneos em ambos os países.

\footnotetext{
${ }^{1}$ SMITH, Adam. “An Inquiry Into The Nature And Causes Of The Wealth of Nations”. 1776.

${ }^{2}$ RICARDO, David. “On The Principles of Politicas Economy And Taxacion”. Third Edition, 1821.

${ }^{3}$ HECKSCHER, Elin F. The Effect of Foreign Trade Theory of International Trade. In: ELLIS, H. S.; METZLER, L. A. (Eds.) Readings on The Theory of International Trade. Londres: George Allen and Unwin Ltd, 1950, pp. 272-300 (1919); OHLIN, Bertil G. Interregional and International Trade. Boston: Harvard University Press, 1933.
} 
A ideia de um país se especializar na produção do bem que ele tem maior dotação fatorial faz com que um país rico em terra produza alimentos, de modo que ele será designado como terra-intensivo. Em contrapartida, um país rico em trabalho irá se especializar na produção de tecidos e será caracterizado como trabalho-intensivo. Essa classificação distingue bem o padrão de comércio internacional estabelecido pela teoria de Heckscher-Ohlin. Vale apenas ressaltar que quando se refere ao termo abundância de fatores, está-se falando em termos relativos, de tal forma que nenhum país será abundante em todos os fatores de produção. Neste sentido, o intercâmbio de mercadorias é uma troca indireta de fatores de produção, até que o preço destes fatores seja equalizado.

O que podemos observar é que mantidas as hipóteses fundamentais da ortodoxia clássica e neoclássicas - concorrência perfeita, pleno emprego, funções de produção estáveis e iguais entre empresas/países (difusão livre e imediata de tecnologia) e retornos constantes de escala — os padrões de especialização relativa de cada país conformam-se através de ajustamentos em preços e quantidades, sem alterar o nível setorial ou global de utilização de recursos — ou melhor, sem alterar o nível da renda. Isso significa dizer que o comércio internacional interfere na alocação intersetorial de recursos, quantidades e preços, sem afetar o nível da atividade econômica, acarretando ganhos de comércio para todos os participantes.

Mais recentemente, propuseram-se abordagens dos impactos das economias de escalas e da concorrência imperfeita no comércio mundial, com a mesma conclusão favorável à liberalização comercial. Um dos autores mais conhecidos dessa linha de pensamento é o economista norte-americano Paul Krugman. A ideia básica é a de que geralmente as indústrias são caracterizadas por operarem em economia de escala ou com rendimentos crescentes e que as economias de escalas podem ser internas (dependendo do tamanho da firma) ou externas (dependendo do tamanho da indústria). Além do mais, segundo essa teoria, o comércio não necessita ser resultado das diferenças das vantagens comparativas (Krugman e Obstfeld, 2001). De certo modo, este argumento restaura a defesa smithiana das vantagens do livre-comércio, graças à relação entre a divisão do trabalho e a extensão dos mercados. A integração comercial permitiria a ampliação dos mercados, das escalas de produção e da divisão do trabalho, permitindo o aprofundamento complementar de especializações eficazes internacionalmente, ainda que iniciadas "aleatoriamente".

Os pressupostos utilizados na teoria de economia de escala são basicamente os mesmos trabalhados no modelo neoclássico, onde há uma relação $2 \times 2 \times 2$, isto é, dois fatores de produção (capital e trabalho), dois países e dois produtos comercializados. No entanto, segundo esse modelo, a diferença em relação ao modelo neoclássico reside no fato de que a estrutura de mercado teorizada é diferente. A estrutura de mercado era antes considerada como em concorrência perfeita, que trabalha com rendimentos constantes, já no modelo de economia de escala, a estrutura de mercado predominante é a concorrência imperfeita que opera com rendimentos crescentes de escala. A ideia é a de que em uma estrutura de mercado em que as firmas apresentam economia de escala, pode existir economia de escala externa (que ocorre quando o custo por unidade produzida depende do tamanho 
da indústria, e não necessariamente do tamanho de qualquer firma) e economia de escala interna (quando o custo por unidade produzida depende do tamanho de uma firma individual, e não precisamente de toda a indústria).

A consequência da economia de escala é o colapso da concorrência perfeita, de modo que o modelo mais adequado para analisar o comércio é o mercado de concorrência imperfeita. Krugman e Obstfeld mostram que segundo a ideia das economias de escala, cada país deve concentrar-se na produção de um número limitado de bens, pois com os países produzindo uma quantidade reduzida de produtos, cada um poderá produzir em uma escala maior do que se tentasse produzir uma maior variedade de bens. Sendo assim, o comércio internacional possibilita que cada país produza uma variedade restrita de bens que proporcione a obtenção de vantagens de economia de escala sem sacrificar a variedade de consumo, de tal forma que o comércio internacional amplia a variedades dos bens disponíveis no mercado. A análise do modelo de concorrência monopolística deixa em evidência que as empresas, ao se inserirem no comércio internacional, ampliando o mercado mundial, proporcionarão maiores ganhos de escala e maior variedade de produtos ofertados no comércio, com um equilíbrio de preços no longo prazo mais benéfico ao consumidor. Logo, a conclusão básica do modelo de economia de escala é a de que o comércio internacional é positivo para o desenvolvimento econômico das nações na medida em que ele amplia e integra o mercado, proporcionando ganhos para todos os países envolvidos.

Em suma, independentemente das versões do argumento liberal ou da "nova teoria do comércio internacional" com o pressuposto de economias de escalas e da concorrência imperfeita no comércio mundial, alega-se que as diferenças internacionais não implicariam assimetrias mas complementaridades mutuamente vantajosas: os ganhos de comércio resultantes seriam distribuídos em um jogo de soma positiva, de forma que os ganhos de uns não seriam feitos (na ausência de externalidades) às custas das perdas de outros. Mesmo aqueles deslocados pela concorrência com importados poderiam se especializar, a maior ou menor prazo, em linhas de produção e exportação mais vantajosas que antes. A longo prazo, portanto, o comércio internacional não afetaria o nível de emprego de recursos entre os países, mas apenas sua alocação intersetorial, aumentando a renda real graças aos ganhos de especialização.

\section{ARGUMENTOS ANTILIBERAIS NA ANÁLISE DO COMÉRCIO INTERNACIONAL}

A despeito da coerência lógica do argumento liberal, vários estudos refutaram empiricamente a assertiva de que o perfil da estrutura produtiva e a especialização comercial não contam substancialmente para o desempenho econômico relativo, exigindo que questionemos as suposições teóricas do liberalismo econômico. Se quisermos entender o modo como as diferentes formas de especialização produtiva e inserção comercial influenciam o desempenho econômico relativo dos países, é 
necessário contrapor à visão liberal a constatação de que o comércio não afeta apenas a alocação de recursos, mas também os diferenciais internacionais de crescimento da renda. E explicar por que a diversidade de especializações e/ou de competitividade nas mesmas especializações "conta" para explicar diferenciais de crescimento e, ademais, por que as políticas dos Estados nacionais "contam" para definir a distribuição dos ganhos e perdas envolvidas nas interações econômicas internacionais.

Sendo assim, tirante considerações doutrinárias, é necessário reconhecer que o padrão de comércio internacional é marcado por assimetrias, não apenas herdadas mas também construídas ao longo do tempo. Uma linha teórica que tem apresentado e ganho demasiada consistência na análise do comércio internacional, tendo como um das principais questões analisar os impactos das mudanças tecnológicas no comércio internacional, é a chamada teoria evolucionária ou institucional.

Após a Segunda Guerra Mundial, a economia mundial passou por grandes transformações de ordem estrutural, principalmente em relação à indústria — com relevantes consequências para o setor de alta tecnologia - momento este em que as mudanças tecnológicas implicaram uma profunda necessidade de um novo paradigma teórico para maior compreensão do comércio internacional, pois ficava em evidência que o mercado é um locus de confronto e de rivalidade entre agentes, onde se exercem relações de poder, poder este conferido pela apropriação (privada) de vantagens absolutas de custo e/ou qualidade, onde a fonte de dinamismo do sistema econômico capitalista é a constante criação e recriação de assimetrias entre as unidades econômicas, assimetrias resultantes da apropriação de vantagens absolutas (de custo e/ou qualidade). Logo, a força motriz básica da geração de vantagens absolutas no processo concorrencial (e, portanto, da criação de assimetrias entre os agentes) é a inovação. Mediante essas transformações, ficavam nítidas as deficiências teóricas dos modelos clássicos, neoclássicos e da nova teoria do comércio internacional de economia de escala e concorrência imperfeita, já que seus pressupostos básicos não respondiam aos desafios e mudanças que o mundo real estava atravessando.

Nos inúmeros trabalhos de autores da corrente teórica institucionalista, como Archibugi e Michie $(1997,1998)$ e Dosi et al. (1990), os autores citam a importância do trabalho do economista alemão Friedrich List, o qual elaborou fortes críticas ao pensamento clássico já no século XIX, levando em consideração as assimetrias que predominavam no comércio internacional, principalmente com relação as diferenças tecnológicas entre as nações. Para o economista alemão, a economia clássica, deixando de levar em consideração os interesses nacionais conflitantes, ignora completamente o caráter hierárquico do comércio internacional, ao defender que o livre-comércio seria o melhor caminho para levar todos os países ao mesmo estado de natureza de bem-estar.

Para o autor, a divisão do trabalho reflete a atividade humana que produz bens materiais ou valor de troca que proporciona aumento do capital material de uma nação. No entanto, as forças produtivas têm como base o trabalho intelectual, a 
produção do conhecimento humano como variável de caráter produtivo, o que implica a teoria das forças produtivas elaborada por List (1841), a qual está relacionada a todo desenvolvimento de descobertas, invenções e progresso tecnológico, dando ao conhecimento grande importância para promover o desenvolvimento econômico das nações, fato este que se contrapõe ao pensamento clássico que considera o trabalho meramente físico como a única força produtiva. Logo, segundo o pensamento de List (1841), o atual estado das nações é o resultado do acúmulo de todas as descobertas, invenções, melhorias, aperfeiçoamento e atividades de todas as gerações passadas, ou seja, as vantagens da nações são criadas e não herdadas.

O autor ainda afirma que o mais importante em reconhecer a importância das forças produtivas como variável-chave no desenvolvimento econômico das nações, é que ela implica uma forte atuação do Estado na economia no sentido de promover fortes investimentos na infraestrutura do país, com o objetivo de desenvolver o setor manufatureiro (no período o setor de alta intensidade tecnológica), de modo que ele possa se inserir no comércio internacional de forma mais competitiva. Veja que a teoria das forças produtivas está estritamente relacionada com o surgimento e fortalecimento da industrialização, fazendo uma clara distinção entre o poder que um país com o domínio do setor manufatureiro tem no comércio internacional em relação a um país concentrado na produção de produtos primários, evidenciando a importância da industrialização para um país alcançar maior autonomia nas relações internacionais. Com a ideia de forças produtivas, o autor deixa claro que o livre-comércio não proporciona o desenvolvimento das nações sem a formulação de políticas públicas no sentido de proteger a indústria nascente, setor este essencial para um país alcançar melhor inserção externa. Deste modo, para List (1841), a industrialização era um fator fundamental para que as economias lograssem maturação econômica, de tal modo que para as nações ainda em estágios menos avançados, uma política protecionista seria um instrumento necessário para os países expandirem suas forças produtivas com o desenvolvimento da manufatura. O autor afirmava que não reconhecer a importância das forças produtivas como mecanismo fundamental para o desenvolvimento econômico, em detrimento da crença na teoria dos valores de troca dos clássicos, seria não reconhecer o poder das manufaturas numa economia. Sendo assim, o autor afirmava que "uma nação que troca produtos agrícolas por artigos manufaturados estrangeiros é um indivíduo com um braço só, sustentado por um braço estrangeiro" (List, (1841 [1983]), p. 113).

A partir da leitura crítica de List e autores institucionalistas, uma observação plausível é perceber que a forma como os modelos clássicos e neoclássicos são apresentados parece implicar uma naturalização das relações do comércio internacional, isto é, o país quando inserido no comércio exterior, especializado na produção de um determinado bem, não teria condições de transformação ou mudança em sua posição estabelecida pelo padrão de comércio internacional quando orientado pela teoria das vantagens comparativas e de dotação fatorial. Na verdade, o 
que fica em evidência é uma relação estática das relações do comércio internacional segundo os dois modelos apresentados.

Para Dosi et al. (1990), uma das principais deficiências da teórica clássica e neoclássica reside no fato de considerar as mudanças tecnológicas como uma variável exógena ao sistema econômico e com isso não compreender que as transformações tecnológicas e inovações são propriedades inerentes ao processo econômico. Para esses autores, o relaxamento (ainda que parcial) das hipóteses menos realistas, quais sejam: concorrência perfeita, retornos constantes de escala, mobilidade de fatores, difusão livre e imediata de tecnologia e funções de produção, em modelos de extração neoclássica, implica indeterminações relativas à direção e volume do comércio internacional. Este parece ser o dilema das tentativas de relaxamento de modelos de ortodoxos: uma vez introduzidas alterações em seus pressupostos básicos - na tentativa de incorporar contribuições teóricas da heterodoxia econômica (menos afeita a construções axiomáticas puras e mais preocupada com a aderência de suas hipóteses ao mundo real, ainda que com perda da elegância formal) —, estes modelos perdem sua consistência e, ao fazê-lo, também seu poder explicativo.

Segundo Dosi (1988), os modelos clássicos e neoclássicos estão assentados em pressupostos teóricos heroicos, como a redução dos indivíduos ao conceito de agente econômico racional representativo, as diferenças tecnológicas entre os países podendo ser adequadamente representadas por uma função de produção e uma estrutura de mercado de concorrência perfeita regida pelo laissez-faire, a qual sempre tende a um equilíbrio econômico de Walras, através da mão invisível do mercado. Segundo os autores, esses pressupostos são marcados por fortes inconsistências teóricas por não levar em consideração que as expectativas racionais não podem ser vistas como estacionárias em um sistema econômico que está em constantes transformações. As mudanças dos padrões tecnológicos e institucionais exigem um modelo teórico que propicie a compreensão de um comércio internacional marcado pelas assimetrias de natureza tecnológica, inovações, ambiente competitivo e organizacional entre os países, fatores estes que têm como consequência um ambiente dinâmico e, concomitantemente, incerto para os agentes econômicos. A tecnologia não pode ser reduzida a livre informação gratuita disponível no mercado, pelo contrário, cada paradigma tecnológico tem sua forma específica; ordenados, cumulativo, são padrões de mudanças técnicas irreversíveis, com cada país tendo sua especificidade (fato este que origina fortes diferenciações de inserção entre os países no comércio internacional).

Em seus trabalhos, Kaldor $(1972,1977,1981)$ elabora sua crítica à ortodoxia econômica, no campo do comércio internacional, concentrando-se basicamente em três de suas hipóteses fundamentais, quais sejam: existência de funções de produção iguais e conhecidas para todos os agentes, ou seja, a tecnologia e a eficiência na sua exploração são iguais; concorrência perfeita; e retornos constantes de escala funções de produção são lineares e homogêneas para todos os processos de produção. O autor defende duas hipóteses fundamentais: 1 . a existência de diferenciais nas elasticidades-renda da demanda entre vários produtos/setores, às quais se as- 
sociam capacidades distintas de geração de renda e emprego; 2. a existência de retornos crescentes de escala (associados a economias de escala estáticas e dinâmicas).

Em relação à primeira hipótese, Kaldor $(1972,1977)$ estabelece uma relação causal entre inserção setorial de cada economia e seu potencial de geração de renda e emprego recuperando a versão dinamizadora do multiplicador de comércio exterior de Harrod, que associa a taxa de crescimento da renda àquela das exportações (componente autônomo da demanda), dividida pela elasticidade de renda delas. Neste sentido, e através da operação dos efeitos multiplicador e acelerador neo-keynesiano, a elasticidade de renda das exportações aparece, neste referencial teórico, como a variável-chave que vincula a demanda (neste caso, o seu componente externo) à geração da renda. Da mesma forma, a condição de equilíbrio de comércio exterior envolve não somente as elasticidades-renda associadas às exportações efetuadas mas também aquelas às importações realizadas.

Assim, e dado que se postulam, de um lado, a relativa estabilidade das cestas de consumo (e baixas elasticidades de substituição entre produtos) e, de outro, a heterogeneidade das elasticidades-renda da demanda dos diferentes produtos que vão compor as pautas de exportação e importação, a variável de ajuste entre as importações e exportações de cada economia é o seu nível de renda e emprego e não os preços e a quantidade. Neste sentido, Kaldor $(1972,1977)$ enfatiza duas proposições básicas: 1 . a dependência das variações das importações relativamente às variações da renda real; e 2. a elasticidade-renda das exportações como elemento fundamental na explicação do crescimento das exportações e a habilidade inovativa como fator básico na definição destas elasticidades-renda.

Para Kaldor (1972,1977), a crítica primordial que deve ser formulada é em relação à hipótese de concorrência perfeita, só sustentável a partir da premissa de retornos constantes de escala. As implicações dinâmicas do abandono desta hipótese - o que conduz, adicionalmente, ao abandono da hipótese de igualdade das funções de produção - são bastante exploradas na chamada literatura institucionalista. As assimetrias entre os agentes como móvel de mudança (endógena ao sistema) é, de fato, uma proposição fundamental comum a todos esses autores.

As hipóteses e críticas elaboradas por Kaldor são formas de apresentar e evidenciar melhor o argumento cepalino (de grande relevância para os países da América Latina) sobre a restrição externa dos países latino-americanos na época do crescimento primário-exportador, dado que predomina relativa inelasticidade-renda das exportações periféricas de bens primários e, simultaneamente, alta elasticidade-renda de suas importações de manufaturados.

Os trabalhos da Comissão Econômica para a América Latina e Caribe (CEPAL), tendo como um dos principais representantes Raul Prebisch, tem como uma das maiores contribuições a identificação da existência de deterioração nos termos de troca entre os países centrais e os periféricos, o que tornava evidente que o comércio mundial não estava sendo favorável ao desenvolvimento dos países da periferia da América Latina. A solução, portanto, seria um profundo processo de industrialização dos países da periferia através do processo de substituição de importações. Prebisch 
fez fortes críticas aos modelos clássico e neoclássico, ao afirmar que a divisão internacional do trabalho defendida por esses modelos é desmentida pelos fatos, pois os benefícios do desenvolvimento econômico não chegaram aos países periféricos, ficando limitados apenas aos países centrais e deixando claro o desequilíbrio dos frutos do comércio internacional.

Prebisch (1949) identifica nas relações internacionais entre os países do centro e da periferia desigualdade de produtividade nas trocas comerciais, de tal forma que ficava evidente a não distribuição equitativa dos frutos do progresso técnico. Segundo o autor, com a elevação da produtividade na indústria através do progresso técnico, deveria haver uma redução dos preços dos produtos manufaturados mais do que proporcional aos preços dos produtos primários, já que a elevação da produtividade reduz os custos de produção. Caso isso acontecesse, as teorias clássica e neoclássica estariam corretas e os benefícios do comércio internacional atingiriam todas as nações de forma equitativa. No entanto, não foi isso que ocorreu, pois se observa que a elevação da produtividade nos países centrais não teve como contrapartida a redução dos preços relativos dos bens manufaturados, pelo contrário, elevaram-se proporcionando maiores ganhos para os países mais desenvolvidos e aumentando a renda dos empresários e dos fatores produtivos dessas nações.

Para Prebisch $(1949,1952)$, a natureza do desequilíbrio entre nações reside no fato de que o progresso técnico reduziu a proporção em que os produtos primários intervêm nos valores dos produtos finais e isso teve como consequência uma redução da demanda global por produtos primários. Por outro lado, a demanda por produtos industrializados tem uma forte tendência a aumentar. Prebisch (1949) afirmava que as importações de produtos primários tendem a crescer menos proporcionalmente do que a renda real, o que demonstra que a elasticidade-renda da demanda dos produtos primários é menor do que 1 , ou seja, na medida em que a renda aumentar, a demanda por produtos primários tende a crescer menos que proporcionalmente. O contrário ocorre com os produtos industrializados, pois a elasticidade-renda da demanda é maior do que 1, de tal forma que na medida em que a renda aumentar haverá um aumento mais que proporcional da demanda por esses bens. Isso tem fortes implicações para os países da periferia da América Latina, que tem sua produção concentrada em produtos primários e uma pauta importadora baseada em bens industrializados.

Segundo o autor, isso ocasionava uma deterioração dos termos de troca entre os países de tal forma que provocava um desequilíbrio de renda entre o centro e a periferia, pois os países periféricos sofriam uma profunda desigualdade nos termos de troca na medida em que tinham que importar produtos industriais e, por outro lado, exportava fundamentalmente produtos agrícolas. Portanto, Prebisch (1949) afirmava que as exportações dos países periféricos se mostravam insuficientes para suprir as suas necessidades de importações, as quais vinham crescendo cada vez mais (Prebisch, 1949, p. 73). O autor defende a industrialização substitutiva dos países periféricos como um mecanismo de mudar a composição da pauta de importações e exportações e, consequentemente, elevar a sua renda através da dinâmica do progresso técnico. Desta forma, o desequilíbrio do balanço de pagamentos 
agravado pela deterioração dos termos de troca nas relações comerciais seria atenuado, diminuindo a vulnerabilidade externa dos países periféricos.

A apresentação das teorias do comércio internacional até aqui abordadas deixa em evidência que as relações intraestatal e interestatal não são marcadas pela perfeita harmonia, mas sim em relações de poder e dominação, além de se constatar que na economia mundial predominam estruturas de mercado altamente concentradas, com as inovações e a P\&D exercendo forte influência nas formas de inserção externa de cada nação. Para Nelson (1993), as mudanças estruturais ocorridas na economia mundial estão estritamente relacionadas com a elaboração de Sistemas Nacionais de Informações que são específicos para cada país, levando em consideração as suas peculiaridades, mas sempre com o objetivo comum de avançar no progresso tecnológico e inovações que propiciem melhor inserção no comércio exterior. O autor afirma que há um novo espírito de "Techno-Nationalism", onde há uma forte crença nas capacidades tecnológicas das empresas nacionais como aspecto-chave para lograr poder de competitividade, aliada com a convicção de que os recursos necessários estão envolvidos em um sentimento nacional que pode ser construído por ações nacionais. Para Ostry e Nelson (1995), as instalações de P\&D, formadas por equipes de cientistas, universitários e engenheiros, interligados a empresas, universidades e/ou agências governamentais, são os principais veículos e atores institucionais que proporcionam a emersão de novos produtos originados do avanço tecnológico. Essa constatação de Ostry e Nelson apenas confirma a ideia de que as vantagens competitivas das nações no comércio internacional são criadas e não herdadas.

É importante salientar aqui — para melhor compreensão da natureza da construção e acumulação de vantagens competitivas — quais são as características dos setores de alta tecnologia e quais suas implicações, como bem lembram Archibugi e Michie (1998). Os grupos de produtos de alta tecnologia estão relacionados naqueles que incorporam, direta, ou indiretamente, através dos bens intermediários utilizados na sua produção, relativa intensidade em Pesquisa e Desenvolvimento (P\&D) em seus insumos. Outras características comuns são igualmente importantes na definição das vantagens competitivas das empresas na produção e comércio de produtos de alta tecnologia: i) o efeito cumulativo de vantagem inovadora, caracterizada por íngremes curvas de aprendizagem com significativa dinâmica das economias de escala, ii) a capacidade de geração de economias externas positivas, em termos de hard-to-appropriate com repercussões de uma atividade para outra; iii) ambiente das estratégias oligopolistas, em um número pequeno de grandes empresas interdependentes que concorrem através do comércio e do investimento transnacional.

Nas indústrias com estas características, a vantagem relativa de um país vis-à-vis outros países, resulta não só das diferenças nacionais em relação às vantagens de dotação fatorial, mas como a teoria e a evidência empírica sugerem e confirmam, é também uma função do diferencial tecnológico, conhecimento e capacidade, que são criados e reproduzidos através do tempo. Nas últimas décadas, indústrias de alta tecnologia têm sido o foco de preocupação especial para os governos de todos 
os grandes países. Uma variedade de razões econômicas está por trás dessa preocupação: i) as indústrias de alta tecnologia são responsáveis por grandes e crescentes ações de comércio e investimento nos setores industrializados; ii) as indústrias de alta tecnologia estão muitas vezes na origem de importantes inovações tecnológicas, com os prováveis benefícios de transbordamento das inovações limitando-se aos níveis do comércio intraindústria e interindústria; iii) a maioria das empresas de altatecnologia é de indústrias de alta produtividade e pagam salários mais elevados do que outros setores produtivos.

Freeman e Hagedoorn (1995), através de ampla pesquisa empírica em relação aos gastos dos países com $\mathrm{P} \& \mathrm{D}$, confirmam a hipótese de que as vantagens competitivas são construídas e não herdadas. Através dos indicadores de P\&D, os autores mostram que P\&D são altamente concentradas nos países desenvolvidos e, por outro lado, os países em desenvolvimento apresentam baixa performance no desenvolvimento de $P \& D$. Essa concentração de $P \& D$ nos países avançados é marcada pelas alianças estratégicas (característico da globalização econômica) entre grandes corporações desses países. Outro ponto importante é que as transferências de tecnologia que são realizadas através das alianças estratégicas se concentram também entre esses países. Portanto, o que se pode constatar é que a convergência de desenvolvimento econômico através do progresso tecnológico e de inovações está restrita aos países desenvolvidos em detrimento dos países em desenvolvimento.

Um fato primordial no processo de internacionalização da alta tecnologia, com alta concentração nos países desenvolvidos, é a importância das empresas multinacionais nas atividades tecnológicas e no jogo do comércio internacional. Umas das principais estratégias das empresas multinacionais é a cooperação empreendida com governos e comunidades científicas, com o objetivo de ampliar de forma substancial as atividades em $P \& D$ e registro de patentes para lograr maiores degraus no processo de inovações e progresso tecnológico. Archibugi e Pianta (1992) constatam que a internacionalização da tecnologia e do crescimento da especialização setorial dos países e das grandes empresas tem conduzido, ao longo da década de 1980, a um novo modelo de cooperação em atividades inovadoras tanto através das fronteiras como também entre diferentes instituições - tais como centros de pesquisa de ciência e tecnologia, indústria e agências governamentais. Os três principais aspectos da estratégia cooperativa são: 1) a cooperação internacional entre as empresas; 2) o desenvolvimento de programas de alta tecnologia combinando os esforços dos diferentes agentes; e 3) maior colaboração internacional entre os cientistas.

A evidência empírica parece sugerir que as mudanças em termos de competitividade no comércio de alta tecnologia constituem tendências de longo prazo. Tais mudanças ultrapassam os limites das políticas macroeconômica e/ou flutuações cambiais, cabendo aos fatores estruturais um forte papel. Obviamente que, em uma economia mundial marcada pelo comércio de alta tecnologia, cabe aos governos nacionais um papel relevante, com novas formas de intervenção pública na tentativa de corrigir as assimetrias que preponderam no comércio internacional.

As atividades da comunidade científica, as empresas e as agências governamen- 
tais propiciam a emersão de um conjunto específico de instituições e regulamentações técnicas que regulamentam e direcionam a natureza e a direção das constantes mudanças nos padrões tecnológicos. Em alguns países, o governo financiou instituições, laboratórios públicos e universidades que cooperam com o setor empresarial; em outros países, as empresas criam sua própria rede para compartilhar know-how e as informações técnicas. O montante dos recursos mobilizados, os setores industriais escolhidos para se tornarem os campeões nacionais direcionados à inovação, a importância do setor militar, o tipo de instituição envolvida, bem como os critérios de seleção de inovações (custo, desempenho, qualidade etc.) são todos fatores críticos na definição do desempenho nacional e tecnológico do estilo.

É importante notar que a nação não é um fator irrelevante nesse processo de internacionalização da tecnologia, de modo que o Estado ainda exerce papel crucial na atividade econômica através da implementação de política de inovações, incluindo política industrial, programa de alta tecnologia, polícia de comércio exterior, em síntese, elaboração de um Sistema Nacional de Inovações que tenha como objetivo primordial propiciar aos países grandes avanços no progresso tecnológico para acompanhar as mudanças constantes que ocorrem na internacionalização da tecnologia.

Independentemente dos posicionamentos pró ou contra as intervenções do Estado na economia, um fato inquestionável é a importância que o setor de bens de capital tem no desenvolvimento tecnológico e nas inovações, de tal forma que se torna um dos ramos industriais mais importantes na estrutura industrial de qualquer país, principalmente quando se observa sua relevância para propiciar melhor inserção no comércio exterior. Fajnzylber (1983) afirma que para se compreender o crescimento e a internacionalização do progresso técnico e das inovações é demasiadamente importante analisar a dinâmica da indústria de bens de capital.

$\mathrm{O}$ autor afirma que a magnitude e a estrutura interna do setor de bens de capital é um fator de muita importância para a análise da dinâmica industrial, pois a sua condição de portador do progresso técnico exerce influência nas modificações que experimenta a produtividade da mão de obra e dos investimentos, em consequência, da competitividade internacional das economias nacionais. O funcionamento do setor produtor de bens de capital exerce influência nos fatores institucionais, tais como nas relações entre o setor público e o setor privado, assim como na internacionalização do setor industrial. Em boa medida, a indústria de bens de capital se constitui no fio condutor para a reflexão sobre a especificidade que adota o sistema industrial nacional. Particularmente, a magnitude da sua presença e comportamento marca uma das diferenças fundamentais entre as economias industriais avançadas e as semi-industrializadas, em especial nos países da América Latina. Além do mais, a indústria de bens de capital produz um efeito multiplicador relevante que tem efeito de difusão para todos os níveis da economia, tais como na qualificação de mão de obra e elevação da produtividade em todo o resto dos setores industriais e, por consequência, ganho de competitividade no comércio internacional. 


\section{CONSIDERAÇÕES FINAIS}

A discussão elaborada chama a atenção para os seguintes pontos:

a) há ramos cujas exportações crescem ao longo do tempo a uma taxa maior que o comércio internacional, enquanto em outros o inverso é verdadeiro: ceteris paribus, os países especializados em ramos mais dinâmicos desfrutam de melhores perspectivas de crescimento da renda que outros, estimulados pelo multiplicador do gasto e relativamente menos vulneráveis a restrições cambiais;

b) outra maneira de distinguir as perspectivas de crescimento é avaliar a elasticidade-renda das exportações e importações: países especializados na exportação de bens de demanda fortemente elástica e na importação de bens de demanda relativamente inelástica têm melhores perspectivas de crescimento, e vice-versa;

c) em especial nos ramos de exportações industriais líderes do crescimento comercial mundial, as vantagens competitivas são construídas por economias de escala estáticas e/ou dinâmicas (aprendizado e inovação); as especializações resultam da construção de vantagens absolutas, e as barreiras à entrada de novos concorrentes tendem a ser cumulativas e crescentes, pelo menos até que novas oportunidades de diferenciação de produto e processo esgotem-se e transfiram-se para novos ramos; esta característica fortemente construída e cumulativa da competitividade difere da exploração de vantagens comparativas "estáticas" dependentes de recursos naturais e baixos salários, em subsetores (industriais ou não) cujo crescimento em valor ao longo do tempo é menor que o do comércio internacional;

d) a característica fortemente construída da competitividade nos ramos industriais articula as condições de demanda e de oferta, à medida que a elasticidade-renda das exportações depende de economias de escala e de inovabilidade de produto/processo; com isso, a polarização internacional entre países exportadores de bens de alta elasticidade-renda e os demais associa-se a perfis de liderança inovativa construída e cumulativa que, uma vez iniciada, é dificilmente reversível em um quadro de livre-comércio;

e) a característica construída e polarizada dos efeitos distributivos dos padrões de competitividade e especialização e sua tendência à cumulatividade é uma justificativa (e não apenas uma explicação) para a virtual ubiquidade da intervenção de Estados na competição comercial internacional, através de políticas comerciais, industriais e tecnológicas ativas e, às vezes, reestruturantes; de fato, se as políticas de Estado podem constituir-se em uma vantagem competitiva nacional em condições em que estas vantagens não são simplesmente herdadas mas construídas e reconstruídas, a competição econômica internacional tende a confundir-se, em parte, com a competição interestatal voltada a influenciar os termos e resultados do comércio internacional - inclusive através de pressões diplomáticas; desta maneira, a capacidade diferencial dos Estados em favorecer as exportações locais na disputa por parcelas de mercado e promover especializações prospectivamente vantajosas é outra fonte de assimetrias. Neste sentido, o que importa é saber quais tipos de orientações, instituições e articulações políticas favorecem a expansão de market shares e especializações produtivas internacionalmente virtuosas e quais as 
desfavorecem - em vez de verificar quais "respeitam" e quais "desrespeitam" os critérios liberais de eficácia inferidos de uma presumida dotação estática/natural de fatores;

f) finalmente, como resultado do padrão diferenciado e assimétrico de competitividade e especialização internacional, do montante e composição da participação dos países nos fluxos de comércio, se distribuiriam limites/estímulos ao crescimento: ao longo do tempo, restrições cambiais ao crescimento são, ceteris paribus, mais esperadas em países cujas exportações perdem parcelas de mercado para concorrentes e/ou que importam bens de maior elasticidade-renda que suas exportações (e vice-versa).

\section{REFERÊNCIAS BIBLIOGRÁFICAS}

ARCHIBUGI, Daniele \& MICHIE, Jonathan (1997) Technology, Globalization and Economic Performance. Cambridge: Cambridge University Press.

ARCHIBUGI, Daniele \& MICHIE, Jonathan (1998) Trade, Growth and Technical Change. Cambridge: Cambridge University Press.

ARCHIBUGI, Daniele \& PIANTA, Mario (1992) The Technological Specialization of Advanced Countries. Dordrecht: Kluwer.

DOSI, G. (1988) Technical Change and Economic Theory. London: F. Pinter.

DOSI, G. et al. (1990) The Economics of Technological Change and International Trade, Brighton: Wheatsheaf.

FAJNZYLBER, F. (1983) La Industrialización trunca de America Latina. México: Centro de Economia Transnacional (CET) - Editorial Nueva Imagen.

FREEMAN, C. \& HAGEDOORN, J. (1995) Technical Change and the World Economy: Convergence and Divergence in Technology Strategies. Aldershot: E. Elgar.

HECKSCHER, Elin F. (1919) "The effect of foreign trade theory of international trade. In: ELLIS, H. S.; METZLER, L. A. (Eds) Readings on The Theory of International Trade. Londres: George Allen and Unwin Ltd, 1950, pp. 272-300.

KALDOR, N. (1972 [1989]). The Irrelevance of Equilibrium Economics. In: TARGETTI, F. e THIRLWALL, A. P. (1989) (Eds). The Essential Kaldor. New York: Holmes \& Meier.

KALDOR, N. (1977 [1989]) Equilibrium Theory and Growth Theory. In: TARGETTI, F. e THIRLWALL, A. P. (1989) (eds). The Essential Kaldor. New York: Holmes \& Meier.

KALDOR, N. (1981 [1989]) "The role of increasing returns, technical progress and cumulative causation in the trade and economic growth". In: TARGETTI, F. e THIRLWALL, A. P. (1989) (eds). The Essential Kaldor. New York: Homes \& Meier.

KRUGMAN, P. R. \& OBSTFELD, M. (2001) Economia Internacional: Teoria e Política. $4^{\mathrm{a}}$ ed. São Paulo: Makron Books.

LIST, Georg Friedrich. (1841 [1983]) Sistema Nacional de Economia Política. São Paulo: Abril Cultural (Coleção Os Economistas).

NELSON, R. et al. (1993) National Innovation Systems: A Comparative Analysis. New York/Oxford: Oxford University Press.

OHLIN, Bertil G. (1933) Interregional and International Trade. Boston: Harvard University Press.

OSTRY \& NELSON (1995) Techno-nationalism and Techglobalism: Conflict and Cooperation. Washington, D.C.: Brookings Institute.

PREBISCH, Raul (1949 [2000]) “O desenvolvimento econômico da América Latina e alguns de seus problemas principais”. In: BIELCHOSWSKY, Ricardo (Org). Cinquenta Anos de Pensamento na CEPAL. Rio de Janeiro: Cofecon/Record, p. 69-136. 
PREBISCH, Raul (1952 [2000]) "Problemas teóricos e práticos do crescimento econômico". In: RICARDO, Bielchoswsky (Org). Cinquenta Anos de Pensamento na CEPAL. Rio de Janeiro: Cofecon/Record, pp. 179-215.

RICARDO, David (1776 [1821]) On The Principles of Political Economy And Taxacion. Third Edition 1821. Batoche Books, Canadá, 2001. Disponível em: http://www.pensamentoeconomico.ecn.br/ economistas/david_ricardo.html. Acesso em: 20 jun 2008.

SMITH, Adam (1981) An Inquiry Into The Nature And Causes Of The Wealth of Nations. 1776. Liberty Fund, 1981. Disponível em: http://www.pensamentoeconomico.ecn.br/economistas/adam smith.html. Acesso em: 20 jun 2008. 